\title{
Maternal passive smoking and the risk of developing wheeze in children: how should we deal with it?
}

\author{
Elida Zairina \\ Affiliation: Dept of Pharmacy Practice, Faculty of Pharmacy, Airlangga University, Surabaya, Indonesia. \\ Correspondence: Elida Zairina, Dept of Pharmacy Practice, Faculty of Pharmacy, Airlangga University, \\ Jl. Dharmawangsa Dalam, Surabaya 60286, East Java, Indonesia. E-mail: elida-z@ff.unair.ac.id
}

@ERSpublications

Cooperation is needed to create smoke-free environments, both private and public, for children and pregnant women http://ow.ly/hdm5300ExJ5

Evidence regarding the adverse effects of maternal smoking and tobacco smoke exposure during pregnancy on the fetus has been recognised in a large number studies; however, smoking during pregnancy is still common. Maternal smoking during pregnancy increases the risk of pregnancy complications (e.g. placental abruption, placenta praevia or premature rupture of the membranes) [1,2] and poor infant outcomes (e.g. sudden infant death syndrome, lower respiratory tract illness, restricted fetal growth, pre-term related death, low birth weight infants, asthma or wheeze) [3-7]. Studies have shown that smoking exposure during pregnancy increases the risks of physician-diagnosed asthma and the development of wheeze in childhood $[3,8,9]$. The risks are even higher when the mother shows pre-natal psychological stress [10]. It is known that wheezing may resolve spontaneously during childhood but may persist into adulthood, particularly in young children with severe asthma [11-13], but the question is, can we cut the risk or even prevent it?

In this issue of the European Respiratory Journal, VARDAVAs et al. [14] report the results of a pooled analysis of 15 cohort studies that participated in the European project ENRIECO (Environmental Health Risks in European Birth Cohorts) [15] to assess the independent effects of active and passive smoking exposure, both pre- and postnatal, on the development of wheeze in children before the age of 2 years. Furthermore, this study describes the development of wheeze in children based on the different sources of exposure and timeframes of pregnancy (prenatal maternal active smoking, prenatal maternal passive smoking and children's postnatal passive smoking) and assessed them, both as independent and combined factors. In total, data from $>37000$ mother-child pairs are presented, in $>27000$ of which, second-hand smoke (SHS) exposure and wheeze data were available. The authors report that children exposed to both to passive and active smoking mothers during pregnancy had the highest risk of developing early wheeze. Risk of wheeze was further increased when children were exposed to passive smoke post- and prenatally. Specifically, prenatal exposure to passive smoke was found to have a higher risk of developing wheeze in children than postnatal; however, the combination of both timeframes exposures resulted in an even higher risk. The study also showed that children who had both a familial history of allergy and SHS exposure together with prenatal active smoking had an even higher risk of having wheeze. The study has major strengths in the pooled analysis of the included cohort studies that showed the relationships between the passive and active smoking, pre- and postnatally, with the development of wheeze in children. From this analysis, we can see that each factor, including passive or active smoking, or even tobacco exposure, pre- and postnatally, contributes to wheezing development in children up to 2 years of age.

The prevalence of active and passive smoking was varies among countries [16]. While tobacco smoking rates among pregnant women have decreased over the past 10 years [1], the rates were unchanged in some low- and middle-income countries [17]. However, the used of different methods to report smoking status

Received: May 242016 | Accepted: May 262016

Conflict of interest: None declared.

Copyright @ERS 2016 
among pregnant women may contribute to the reliability of the smoking prevalence in pregnant women. The self-reported questionnaires that were most commonly used in antenatal clinics are often less accurate in identifying smokers among pregnant women [18]. With the majority of pregnant women not revealing their smoking status, the numbers of those who smoked during pregnancy could be underrated [18]. With so much pressure from social, perceived values, and the medical advice for pregnant women to quit smoking, women preferred not to report their smoking status, resulting in low access in any smoking cessation programmes for pregnant women [19]. Therefore, some studies proposed urinary cotinine level measurements or other biomarkers in addition to the self-reported SHS exposure questionnaires in pregnant women $[20,21]$. Despite the underreported smoking prevalence figures in pregnant women, the methods used in reporting the effects of tobacco exposure in the development of wheeze also played a role. Relying on parental report for measuring outcomes such as wheeze may be subject to underreporting and recall bias, which is acknowledged by VARDAVAs et al. [14] as a study limitations.

Many smoking cessation programmes have been created and applied worldwide; however, the burden of disease from SHS exposure is still high [22]. We have learned from VARDAVAS et al. [14] that maternal passive smoking during pregnancy is an independent risk factor for developing wheeze in children up to the age of 2 years. Could the study be used to support the current evidence about the importance of protecting both pregnant women and infants from SHS exposure, either in private or public areas? The answer is "yes". A novel and effective strategy needs to be designed and implemented to prevent tobacco exposure during pregnancy. A well-established public health campaign or clinical intervention could be effective in reducing tobacco exposure in public areas. In the developed world, such as the USA and European countries, both the cost and clinical effectiveness interventions have been well implemented; however, this is not the care in developing countries [23]. As most of developing countries face some barriers to implementation, including low socioeconomic status, low education and lack of support from policy-makers or governments, it is more difficult to implement the interventions. However, this does not mean that it is impossible to implement these interventions. Developed countries such as the USA [24] and Australia [25] have successfully implemented community and population-based interventions including mass media campaigns, telephone quit lines, reducing cost of treatment, tobacco advertising bans, taxation and raising tobacco prices. Most of these methods, particularly complete bans on tobacco advertising and tax increases, might be difficult to implement in developing countries, as some of those governments incomes rely on the money from advertising and taxation. An expensive programme, such as a quit line, could be difficult as well to implement in low-income countries. A national tobacco control programme involving community support might be possible, as it has been successfully implemented in Thailand and Brazil [26]. Less costly public campaigns such as smoking cessation posters or pictures about the harmful effects of passive and active tobacco exposure during pregnancy, placed in the public areas such antenatal clinics, could be helpful.

Finally, we know that tobacco exposure, particularly maternal passive smoking during pregnancy, is harmful for both maternal and neonatal outcomes, but most importantly, we should put more effort into the prevention of tobacco exposure in pregnant women. A close liaison between policy-makers, healthcare professionals and family members is warranted to create a smoke-free environment for pregnant women and children, both in private and public areas.

\section{References}

1 Salihu HM, Wilson RE. Epidemiology of prenatal smoking and perinatal outcomes. Early Hum Dev 2007; 83: 713-720.

2 Miyake Y, Tanaka K, Arakawa M. Active and passive maternal smoking during pregnancy and birth outcomes: the Kyushu Okinawa Maternal and Child Health Study. BMC Pregnancy Childbirth 2013; 13: 157.

3 Gilliland F, Li Y-F, Peters J. Effects of maternal smoking during pregnancy and environmental tobacco smoke on asthma and wheezing in children. Am J Respir Crit Care Med 2001; 163: 429-436.

4 Taylor B, Wadsworth J. Maternal smoking during pregnancy and lower respiratory tract illness in early life. Arch Dis Child 1987; 62: 786-791.

5 DiFranza JR, Aligne CA, Weitzman M. Prenatal and postnatal environmental tobacco smoke exposure and children's health. Pediatrics 2004; 113: 1007-1015.

6 Ben Safta B, Ben Amar J, Dhahri B, et al. Effect of passive smoking in pregnancy on maternal, fetal and neonatal morbidities. Eur Respir J 2014; 44: Suppl. 58, P4183.

7 Dietz PM, England LJ, Shapiro-Mendoza CK, et al. Infant morbidity and mortality attributable to prenatal smoking in the U.S. Am J Prev Med 2010; 39: 45-52.

8 Jaakkola JJK, Gissler M. Maternal smoking in pregnancy, fetal development, and childhood asthma. Am J Public Health 2004; 94: 136-140.

9 Lannerö E, Wickman M, Pershagen G, et al. Maternal smoking during pregnancy increases the risk of recurrent wheezing during the first years of life (BAMSE). Respir Res 2006; 7: 3.

10 Van de Loo KFE, van Gelder MMHJ, Roukema J, et al. Prenatal maternal psychological stress and childhood asthma and wheezing: a meta-analysis. Eur Respir J 2016; 47: 133-146.

11 Sears MR. Consequences of long-term inflammation: the natural history of asthma. Clin Chest Med 2000; 21: 315-329. 
12 Oswald H, Phelan PD, Lanigan A, et al. Childhood asthma and lung function in mid-adult life. Pediatr Pulmonol 1997; 23: 14-20.

13 Oo S, Dmitry S, Ta T, et al. Wheeze presentations to emergency department exponentially decline with increasing age. Eur Respir J 2015; 46: Suppl. 59, PA4180.

14 Vardavas CI, Hohmann C, Patelarou E, et al. The independent role of prenatal and postnatal exposure to active and passive smoking on the development of early wheeze in children. Eur Respir J 2016; 48: 115-124.

15 Vrijheid M, Casas M, Bergström A, et al. European birth cohorts for environmental health research. Environ Health Perspec 2012; 120: 29-37.

16 Janson C, Künzli N, de Marco R, et al. Changes in active and passive smoking in the European Community Respiratory Health Survey. Eur Respir J 2006; 27: 517-524.

17 Bloch M, Althabe F, Onyamboko M, et al. Tobacco use and secondhand smoke exposure during pregnancy: an investigative survey of women in 9 developing nations. Am J Public Health 2008; 98: 1833-1840.

18 Ford RP, Tappin DM, Schluter PJ, et al. Smoking during pregnancy: how reliable are maternal self reports in New Zealand? J Epid Comm Health 1997; 51: 246-251.

19 Shipton D, Tappin DM, Vadiveloo T, et al. Reliability of self reported smoking status by pregnant women for estimating smoking prevalence: a retrospective, cross sectional study. BMJ 2009; 339: b4347.

20 Aurrekoetxea JJ, Murcia M, Rebagliato $M$, et al. Factors associated with second-hand smoke exposure in non-smoking pregnant women in Spain: Self-reported exposure and urinary cotinine levels. Sci Total Environ 2014; 470-471: 1189-1196.

21 Batty GD, Gale CR, Jefferis B, et al. Passive smoking assessed by salivary cotinine and self-report in relation to cause-specific mortality: 17-year follow-up of study participants in the UK Health and Lifestyle Survey. J Epidemiol Community Health 2014; 68: 1200-1203.

22 Öberg M, Jaakkola MS, Woodward A, et al. Worldwide burden of disease from exposure to second-hand smoke: a retrospective analysis of data from 192 countries. Lancet 377: 139-146.

23 Abdullah ASM, Husten CG. Promotion of smoking cessation in developing countries: a framework for urgent public health interventions. Thorax 2004; 59: 623-630.

24 CDC. Reducing tobacco use: a report of of the Surgeon General. Atlanta, US Department of Health and Human Services, 2000.

25 Zwar N, Richmond R, Borland R, et al. Smoking cessation pharmacotherapy: an update for health professionals. Melbourne, Royal Australian College of General Practitioners, 2007.

26 Jha P, Chaloupka FJ. The economics of global tobacco control. BMJ 2000; 321: 358-361. 